\title{
RIITICA SOCIAL EN LA NOCHE DE LOS MUERTOS VIVIENTES Y SU REMAKE: APORTACIONES AL ROL DE LA MUJER EN EL CINE DE TERROR
}

ALBERTO AÑÓN LARA

Doctorando de la Universidad de Córdoba

L92anlaa@uco.es

\begin{abstract}
Resumen: Tradicionalmente se ha tenido la percepción de que la mujer en el cine de terror ha ocupado un rol pasivo que le llevaba a asumir, casi siempre, el papel de víctima, subyugada en todo momento a los personajes masculinos del texto fílmico. Por este motivo, el cine de terror es concebido de forma habitual como un género culturalmente consumido y dominado por hombres, producido por una industria que victimiza y castiga a la mujer una y otra vez. Partiendo de esta premisa, y aprovechando la crítica de corte sociopolítico presente en La noche de los muertos vivientes (Night of the Living Dead, George A. Romero, 1968) y su remake del año 1990, nos planteamos un análisis de la crítica elaborada por Romero al patriarcado en ambas películas y qué aporta esta al rol de la mujer como víctima tradicional del cine de terror.
\end{abstract}

Palabras clave: cine de terror / remake / patriarcado / zombi / George A. Romero.

\section{SOCIAL CRITICISM IN NIGHT OF THE LIVING DEAD AND ITS REMAKE: CONTRIBUTIONS TO THE ROLE OF WOMEN IN HORROR FILMS}

Abstract: Traditionally, it has been perceived that women in horror films have occupied a passive role that led them to assume, most of the time, the role of victim, subjugated at all times to the male characters in the film text. For this reason, horror cinema is usually conceived as a genre that is culturally dominated and consumerized by men, produced by an industry that repeatedly victimizes and punishes women. Starting from this premise and taking advantage of the sociopolitical critique present in Night of the Living Dead (George A. Romero, 1968) and its 1990 remake, we propose an analysis of Romero's critique of the patriarchy in both films and what it contributes to the role of women as traditional victims of horror films.

Key words: horror film / remake / patriarchy / zombie / George A. Romero.

\section{Introducción}

A lo largo de la historia numerosos teóricos han abordado la relación entre el cine y los acontecimientos sociales. El crítico cinematográfico Robin Wood hablaba de ver y analizar las películas enmarcadas en el contexto cultural en el que se producen como una necesidad, ya que lo que ocurre en el cine claramente depende de los acontecimientos sociales y políticos. ${ }^{1}$ En consecuencia, afirmaba que las películas se constituyen como entidades ideológicas vivas que, inevitablemente, dramatizan los conflic- tos que caracterizan nuestra cultura: conflictos de clase, género, raza y orientación sexual. ${ }^{2}$ Ya en 1947, fecha en la que se publica originalmente De Caligari a Hitler: una historia psicológica del cine alemán, Siegfried Kracauer defendía que las películas de una nación reflejan su mentalidad. ${ }^{3}$ El contexto en que se gesta una película, en definitiva, comienza a cobrar importancia, reconociendo así su necesaria inclusión y valoración en el análisis cinematográfico. Sin embargo, autores como Pierre Sorlin, aunque reconocen la enorme relevancia de las

\footnotetext{
* Fecha de recepción: 15 de octubre de 2019 / Fecha de aceptación: 15 de junio de 2020.

1 WOOD, Robin, 2003, p. 3.

2 WOOD, Robin, 2003, p. 7.

${ }^{3}$ KRACAUER, Siegfried, 1985, p. 13.
} 
tesis de Kracauer, consideran que el deseo de ver en las películas un reflejo fidedigno o una transposición exacta de la realidad social es una exageración:

Que la película esté íntimamente penetrada por las preocupaciones, las tendencias y las aspiraciones de la época en que se ha producido, nadie piensa en negarlo. [...] Las divergencias nacen cuando nos interrogamos sobre lo que el cine es capaz de enseñarnos. Kracauer hace de "la mentalidad de una nación" una globalidad; nosotros, por lo contrario, hemos tenido el cuidado de subrayar el carácter estrecho, limitado y parcial de cada una de las expresiones ideológicas de un periodo dado. [...] La cámara registra cosas reales, pero esas cosas no son "la realidad"; son "la vida" percibida, o reconstituida, o imaginada por quienes hacen el filme, y nada nos permite considerarlas más que como representaciones. ${ }^{4}$

La propuesta de Kracauer de relacionar las obras cinematográficas con la sociedad que las ha producido, en cualquier caso, debe ser tomada con reservas, en tanto que "[...] el filme, lejos de describir la realidad bruta, propone una interpretación: el filme no descubre la realidad, sino diversas trasposiciones de la realidad". ${ }^{5}$ No obstante, con todas sus insuficiencias, no cabe duda de que sus planteamientos han pavimentado el camino seguido por multitud de teóricos y críticos que dedican sus esfuerzos a estudiar el cine de terror desde un punto de vista sociológico. Extrapolando esa correspondencia entre las películas y el medio en el que nacen, muchos de estos teóricos "[...] han intuido que el cine de terror es capaz de decir mucho sobre nuestra sociedad y sus convenciones". ${ }^{6}$ Sin embargo, el principal problema al que nos enfrentamos es que la mayoría de estos estudios carecen de unos fundamentos teóricos que sustenten con solidez sus argumentos. En un intento por poner fin a esta laguna teórica, Luis Pérez Ochando realiza en Noche sobre América: Cine de terror después del 11-S (2017) un análisis de las principales teorías sociales empleadas en los estu- dios del género y expone algunas de sus limitaciones metodológicas a la hora de aplicarlas al análisis cinematográfico. ${ }^{7}$

Una de las corrientes teóricas de mayor calado es aquella que toma del psicoanálisis la idea del retorno de lo reprimido, utilizada en el análisis cinematográfico, entre otros, por teóricos como Robin Wood, Reynold Humphries, Carol Clover o Barbara Creed. ${ }^{8}$ Lo reprimido retorna de manera constante en la forma del monstruo, ${ }^{9}$ el cual se convierte en el vehículo perfecto para la expresión de los miedos y ansiedades sociales. Esto ha sido posible gracias a que, a grandes rasgos, el monstruo es entendido como "[...] an embodiment of a certain cultural moment -of a time, a feeling, and a place". ${ }^{10}$ Por tanto, estos deberían ser examinados "[...] within the intricate matrix of relations (social, cultural, and literary-historical) that generate them". ${ }^{11}$ El monstruo se revela como la sombra de la normalidad, un doppelgänger que nos obliga a hacer frente a aquellas inquietudes que hemos reprimido en nuestro interior durante tanto tiempo. ${ }^{12}$

Pérez Ochando hace alusión también a los "Trauma Studies":

[...] un proyecto teórico que [...] pretende crear una disciplina capaz de rastrear una memoria traumática en la cultura y de descubrir cómo la identidad nacional o étnica interactúa con episodios tan horrendos como el genocidio, la guerra, el racismo o la marginación. ${ }^{13}$

Adam Lowenstein (2005), Linnie Blake (2008) o Antonio José Navarro (2016) -este último en el ámbito nacional-, algunos de los principales representantes de estos "Trauma Studies", defienden que el cine de terror tiene la capacidad de codificar los recuerdos traumáticos experimentados por una sociedad y su análisis es lo que nos permite descodificarlos para, en última instancia, conseguir una asimilación cultural de las experiencias traumáticas que se constituye como requisito previo para la cu-

\footnotetext{
4 SORLIN, Pierre, 1985, p. 42.

5 SORLIN, Pierre, 1985, p. 220.

${ }^{6}$ PÉREZ OCHANDO, Luis, 2017, p. 75.

7 Citaremos aquellas que a nuestro juicio son más relevantes para los objetivos planteados en este artículo. Para una información más pormenorizada véase: PÉREZ OCHANDO, Luis, 2017, p. 72-90.

8 PËREZ OCHANDO, Luis, 2017, p. 76.

${ }^{9}$ Entendiendo por monstruo cualquier figura/amenaza que interrumpe de manera súbita el orden natural de las cosas, es decir, la normalidad.

10 COHEN, Jeffrey Jerome, 1996, p. 4.

11 COHEN, Jeffrey Jerome, 1996, p. 5.

12 WOOD, Robin, 2003, p. 72.

13 PÉREZ OCHANDO, Luis, 2017, p. 102.
} 
ración. ${ }^{14}$ Sin embargo, el minucioso análisis histórico que hacen este tipo de estudios se ve lastrado en ocasiones por la falta de una "[...] teorización seria que afiance sus razonamientos". ${ }^{15}$ En este sentido, Pérez Ochando señala Pretend We're Dead: Capitalist Monsters in American Pop Culture de Annalee Newitz como una excepción por su enfoque desde una perspectiva marxista, algo que en la mayoría de estos estudios queda relegado a un segundo plano. Newitz concibe el cine de terror como una expresión metafórica de todo aquello que ha sido reprimido por el capitalismo. ${ }^{16}$

Partiendo de esta premisa, centraremos nuestra atención en la ópera prima de Romero y trataremos de aproximarnos a la crítica que elabora en torno al patriarcado y la enorme influencia que este ejerce en la configuración de los roles y estereotipos de género. Para ello procuraremos, en primer lugar, atender a las particularidades de la narrativa desarrollada por Romero en La noche de los muertos vivientes, con el objetivo de desentrañar cuáles son los elementos que le van a permitir desarrollar dicha crítica. Así mismo, incorporaremos al análisis el remake de La noche de los muertos vivientes (Night of the Living Dead, Tom Savini, 1990), de cuyo guión se encargó el propio Romero, pues introduce importantes matices que complementan el mensaje crítico de la película original. Estudiaremos qué modificaciones y añadidos aporta el remake, respecto a la película de 1968, en lo relativo al rol de la mujer como víctima tradicional del cine de terror.

En definitiva, será el análisis textual y del discurso de La noche de los muertos vivientes y su remake el que nos guíe, a través de la narración y sus metáforas visuales -encarnadas por la figura del zombi-, a la consecución de los objetivos aquí planteados.

\section{Una nueva amenaza, una nueva narrativa}

Abordar algo tan complejo como las características del cine zombi de George A. Romero, por lo amplio del tema, implica una necesaria consciencia de la tradición cinematográfica de la criatura en cuestión. ${ }^{17}$ Consciencia de que el zombi, al ca- recer de una tradición literaria significativa que establezca unas reglas o normas a seguir -como sí ocurre con el vampiro-, es una criatura heterogénea y, en consecuencia, difícil de definir. Es esta carencia la que hace que pueda adaptarse como ninguna otra al contexto social de cada momento y jugar así un papel tan importante dentro de la cultura popular.

Sabiendo esto, debemos entender que el zombi creado por Romero es un tipo de zombi más, el dominante hasta la fecha, eso sí, pero no el único. Un zombi que se distancia de ese pseudo-autómata vinculado al folclore haitiano más oscuro, aquel nacido de rituales propios del vudú que permitían controlar la voluntad de cualquier ser humano. ${ }^{18}$ La distinción debe ser clara y precisa, porque el origen del muerto viviente de Romero, a diferencia del zombi haitiano, sí está ligado de manera estrecha a una tradición literaria con mucha más raigambre como es la del vampiro.

Dejando a un lado por un momento el asunto del vampiro, aunque Romero lo utiliza para construir un modelo narrativo que perdura en el tiempo -la inmensa mayoría de películas del subgénero siguen bebiendo de él hoy en día-, sería absurdo por nuestra parte pensar que el director norteamericano, en su profundo conocimiento de la cultura popular, no se vio influenciado por multitud de elementos. Mismamente los cómics de la editorial EC, como señala Pérez Ochando, "[...] suponen para Romero una pauta estética y temática para su obra". ${ }^{19}$ Tanto es así que, en 1982, junto a Stephen King como guionista, realiza un homenaje a los cómics de terror de EC con la película Creepshow (Creepshow, George A. Romero, 1982). En lo que respecta a La noche de los muertos vivientes, por lo tanto, las influencias temáticas y estilísticas son muchas y muy variadas, pero las que más peso tuvieron fueron aquellas historias, novelas y películas de terror y ciencia ficción de las décadas de 1950-1960 vinculadas a la Guerra Fría, así como ficciones sobre el fin de la humanidad tal y como la conocemos. ${ }^{20}$

De todas ellas la que tiene un mayor impacto en la configuración de su primera película es la novela

\footnotetext{
14 BLAKE, Linnie, 2008, p. 14.

15 PÉREZ OCHANDO, Luis, 2017, p. 105.

16 PÉREZ OCHANDO, Luis, 2017, p. 105

17 Respecto a la tradición cinematográfica del zombi véase: RUSSELL, Jaime, 2016; BISHOP, Kyle William, 2010; SÁNCHEZ TRIGOS, Rubén, 2019 -este último, sobre todo, por ser el estudio más completo hasta la fecha sobre el cine de zombis español-

${ }^{18}$ Sobre el zombi haitiano y sus orígenes literarios, así como antropológicos véase: RHODES, Gary D, 2001, p. 70-88; RUSSELL, Jaime, 2006, p. 9-31; SEABROOK, William, 2005

19 PÉREZ OCHANDO, Luis, 2013, p. 37.

20 BISHOP, Kyle William, 2010, p. 96.
} 

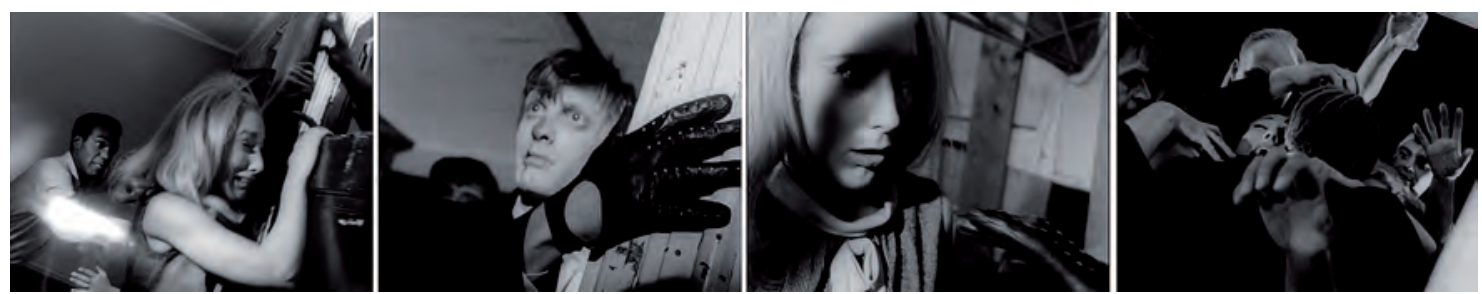

Figura 1. La noche de los muertos vivientes, George A. Romero, 1968.

Soy leyenda (I Am Legend, 1954) de Richard Matheson $^{21} \mathrm{y}$, sobre todo, El último hombre sobre la Tierra (The Last Man on Earth, Sidney Salkow y Ubaldo Ragona, 1964), su primera adaptación cinematográfica. Más allá de las similitudes visuales entre los vampiros de Matheson, los de la versión cinematográfica de 1964, y los zombis de Romero, lo verdaderamente interesante lo encontramos en dos de las características narratológicas empleadas por el escritor norteamericano: el espacio de supervivencia y la inversión de la estructura del conflicto. ${ }^{22} \mathrm{Sin}$ entrar a valorar en qué medida La noche de los muertos vivientes es un ejercicio de reescritura o si, por el contrario, se trata de un simple intento por llevar a la pantalla las novedades incorporadas por Matheson a las narrativas de vampiros, ${ }^{23}$ lo que sí queda claro tras una primera aproximación es que Romero toma estos dos elementos y los hace suyos. Elementos que, por cierto, han permanecido desde entonces como un pilar básico en casi todas las narrativas zombis posteriores.

¿A qué nos referimos cuando hablamos de espacio de supervivencia y de inversión de la estructura del conflicto? Si recordamos, en Soy leyenda la amenaza es colectiva. Ya no encontramos un único vampiro al cual un grupo más numeroso de humanos tratan de eliminar de la faz de la tierra. Al hacer esto, Richard Matheson está apostando por una inversión de la estructura del conflicto, creando así una historia en la que toda la humanidad, a excepción del científico Robert Neville -Robert Morgan en la cinta de Salkow y Ragona-, se ve afectada por un virus que los convierte en vampiros. Esta circunstancia obliga a su protagonista, interpretado por
Vincent Price, a atrincherarse durante las noches en su casa. Eso sí, en su afán por restaurar la humanidad y encontrar una cura al virus que ha provocado este desastre, aprovechará la luz del día para buscar a estas criaturas y acabar con ellas. Al final, más allá de la cuestión numérica, debemos quedarnos con que en esta inversión de la estructura del conflicto Robert Morgan es visto como la verdadera amenaza, lo anormal dentro de una sociedad vampirizada, diluyéndose así la tradicional línea divisoria en la que se sustentaba el cine de terror clásico, es decir, la línea del "ellos" -los monstruos- y "nosotros" -la humanidad-. ${ }^{24}$ De igual manera, el hecho de que el protagonista se refugie en una casa no es baladí, pues nos aleja de los espacios característicos del Gótico y nos acerca al naturalismo de la vida cotidiana.

Lo interesante, como se deduce de nuestras palabras, es que La noche de los muertos vivientes no surge de la nada. Es ese conocimiento de la cultura popular, sobre todo lo relativo al terror y la ciencia ficción, lo que facilita a Romero la articulación de una narrativa que abandona los monstruos y lugares propios de la mitología europea. Estos dos elementos de los que venimos hablando -el espacio de supervivencia y la inversión de la estructura del conflicto- son los que le permiten, en definitiva, crear un modelo narrativo similar al de El último hombre sobre la Tierra. Un modelo que, en esencia, no deja de ser una narrativa de invasión con un final abierto. Autores como Kyle William Bishop llegan incluso a dotar de mayor entidad o especificidad al modelo narrativo creado por Romero, refiriéndose a él con el concepto "zombie in-

21 GAGNE, Paul R., 1987, p. 24.

22 BROWNING, John Edgar, 2011, p. 44

23 WALLER, Gregory A., 1986, p. 275.

${ }^{24}$ RUSSELL, Jaime, 2006, p. 63. 
vasion narrative". ${ }^{25}$ Por el contrario, Andrew Tudor, quien ha estudiado y clasificado con detenimiento los modelos narrativos en el cine de terror, considera que La noche de los muertos vivientes, y en general el cine zombi, se adapta mucho mejor a lo que él llama "metamorphosis narrative". ${ }^{26}$ Independientemente del término empleado, estamos ante un modelo narrativo que, a grandes rasgos, se presta a caracterizar a sus personajes de forma más o menos compleja y enmarcados dentro de contextos sociales específicos. ${ }^{27}$ Por consiguiente, al existir una correspondencia con la realidad social, estas películas proporcionan a sus espectadores una base que les permite identificarse no solo con la historia y sus personajes, sino también establecer un paralelismo entre sus problemas y los hechos que acontecen en la ficción.

En este proceso de identificación, al menos en lo que se refiere a La noche de los muertos vivientes, se conjugan otros elementos que contribuyen también a articular esa correspondencia con la realidad social de la que hablamos. Nos referimos, fundamentalmente, a la elección de un estilo cinematográfico que concede a la película de Romero un realismo que nos lleva a asociar lo que ocurre en la pantalla con los acontecimientos sociales y políticos que sacudieron al país durante la década de 1960, como bien apunta Tony Williams:

His use of lighting and gritty black-and-white photography and a no-holds-barred approach to the horrific incidents gave the film a certain realistic feeling which co-scenarist John A. Russo cites as a key reason the film caught on with critics as well as audiences. ${ }^{28}$

Esta correspondencia con la realidad social, que ya fue percibida tras su estreno en 1968 tanto por críticos como por espectadores, hizo que las lecturas políticas fueran casi inevitables. ${ }^{29}$ Que la situación sociopolítica tuvo un enorme impacto en las lecturas que se hicieron nadie lo pone en duda, puesto que las imágenes de la película contribuían a ello de manera evidente: "Todo parece remitirnos, por un lado, a la guerra de Vietnam y, por otro, a la brutal represión del Movimiento de Derechos
Civiles y a los disturbios tras la muerte de Luther King". ${ }^{30}$ Sí podría, por otro lado, ponerse en tela de juicio el nivel de autoconsciencia de Romero en todo esto y si los subtextos presentes en el film fueron un factor accidental o no. Lo que sí parece claro, según Ben Hervey, es que estos subtextos golpearon a la audiencia mucho más fuerte por la sutileza con la que presentan esa crítica de corte sociopolítico que tanto acabó caracterizando al cine de Romero, es decir, por no haber sido trabajados en exceso. ${ }^{31}$

\section{La Familia como la institución más represiva para la mujer}

La noche de los muertos vivientes nació vinculada a su tiempo, a una época de enorme agitación política y social marcada por la larga sombra de la guerra de Vietnam. Por ende, el cine de Romero "[...] llega al tiempo que comienzan los temblores que habrán de derrumbar la familia americana y el Estado de Bienestar". 32 El convulso clima sociopolítico hizo sacudir los cimientos de la familia nuclear americana y el cine de terror, como señala Tony Williams en Hearths of Darkness: The Family in the American Horror Film (1996), no tardó en recoger los frutos del árbol caído. La guerra de Vietnam tuvo unos efectos devastadores en la representación cinematográfica de la institución familiar, convirtiéndose en uno de los temas centrales del cine de terror de los años setenta. ${ }^{33}$ Así, la familia y el hogar, elementos propios de la naturaleza ordinaria, se erigen como causa de los horribles acontecimientos que ocurren en el film.

La familia nuclear como ente represor se convierte, ya desde la secuencia inicial en el cementerio, en uno de los temas centrales de la película. El acoso y derribo al que Johnny somete a su hermana Barbara en el cementerio no es más que un anticipo de lo que las mujeres de La noche de los muertos vivientes tendrán que soportar. Desde los primeros minutos del film veremos que la familia "[...] será angustia y no reposo, castigo y nunca premio, discusión y jamás paz". ${ }^{34}$ Angustia y castigo sobre

\footnotetext{
25 BISHOP, Kyle William, 2010, p. 94.

26 TUDOR, Andrew, 1989, p. 96.

27 TUDOR, Andrew, 1989, p. 101.

28 WILLIAMS, Tony, 2015, p. 30.

29 HERVEY, Ben, 2008, p. 22.

30 PÉREZ OCHANDO, Luis, 2013, p. 45.

31 HERVEY, Ben, 2008, p. 26-27.

32 PÉREZ OCHANDO, Luis, 2013, p. 36.

33 WILLIAMS, Tony, 1996, p. 129.

34 PÉREZ OCHANDO, Luis, 2013, p. 52.
} 

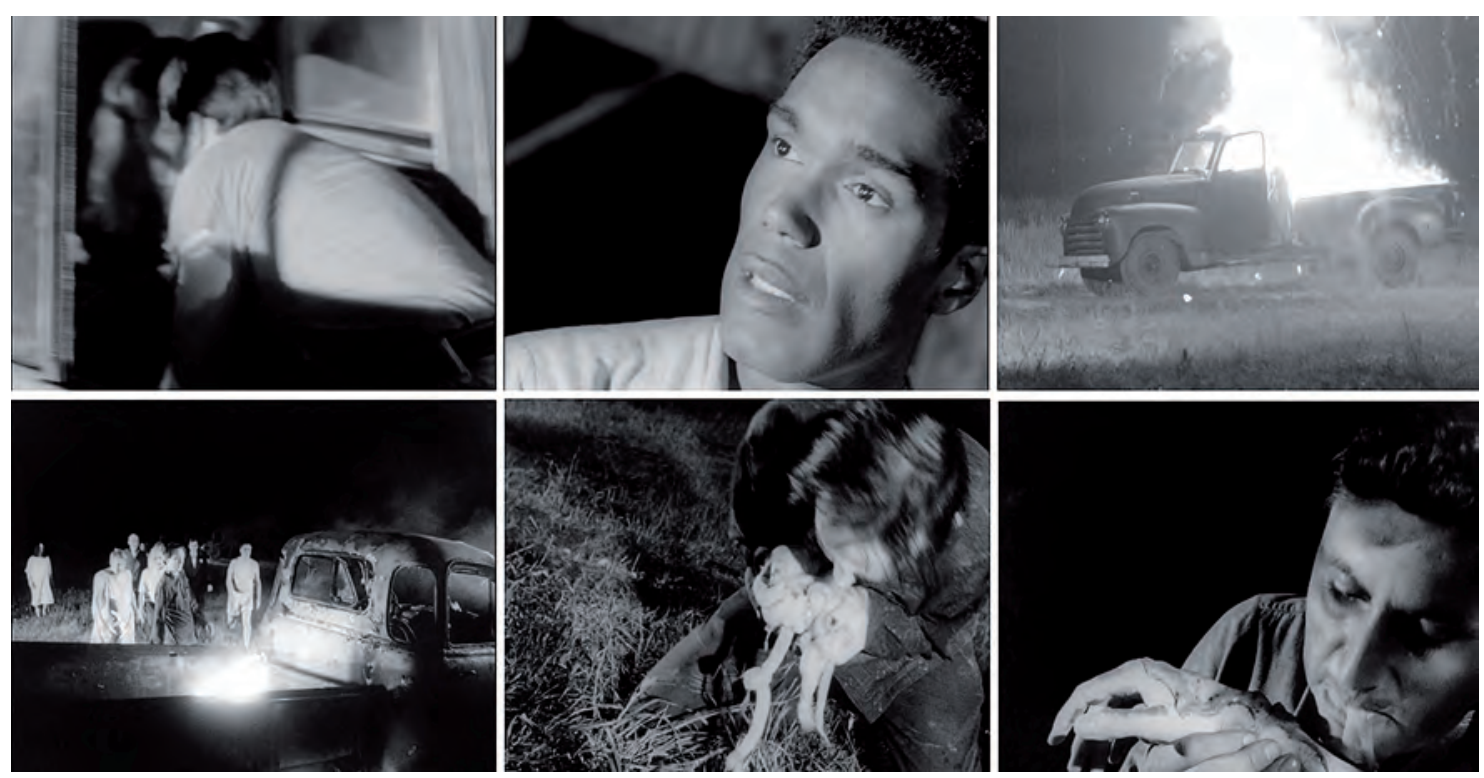

Figura 2. La noche de los muertos vivientes, George A. Romero, 1968.

todo para las mujeres, pues serán quienes sostendrán sobre sus espaldas el insoportable peso del patriarcado y los roles de género.

Barbara desconoce que la casa en la que parece haber encontrado refugio tras huir del primer zombi que aparece en la película -aquel que acaba con la vida de su hermano Johnny en el cementerio- no es más que un espejismo de aparente seguridad. La casa en la que Romero encierra a ella y al resto de sus personajes alberga una amenaza aún mayor que la de los zombis, la amenaza del patriarcado. Patriarcado que se materializa través del conflicto masculino que mantendrán Ben y Harry en un intento por hacerse con el control del grupo. Este conflicto entre dos personajes masculinos -de clases y razas diferentes- que prefieren competir por hacerse con el poder en vez de cooperar por el bien común se mantendrá hasta el final de la película. El patriarcado, personificado por el conflicto que mantienen ambos personajes, se muestra inútil ante el ataque de los muertos vivientes. Además de probarse inútil, este niega cualquier posibilidad de actuación a los personajes femeninos, quienes verán reducidas a la mínima expresión sus posibilidades de sobrevivir.

Si bien todas las mujeres acabarán muriendo como consecuencia de las obligaciones impuestas por los lazos sentimentales y familiares de los que no se pueden liberar, resulta imposible culpabilizarlas de ello porque, como acertadamente señala Harper, la dominación patriarcal que se vive en la casa no cesa en ningún momento. ${ }^{35}$ La fuerte dependencia de Barbara hacia una figura masculina, síntoma de su probada incapacidad para abandonar los valores de género hegemónicos, es lo que la conduce a sumirse en un estado catatónico ${ }^{36}$ del que solo conseguirá salir para ayudar a Helen en su intento por evitar que los zombis entren en la casa. Desgraciadamente no podrán detenerlos y Barbara terminará muriendo a manos de su hermano, quien ha regresado de entre los muertos para devorarla (fig. 1).

Esta sumisión a los roles de género, en cualquier caso, no es una cuestión que afecte de forma exclusiva a Barbara, las otras mujeres en la casa pa-

35 HARPER, Stephen, 2003, p. 3, en línea En: <https://intensitiescultmedia.files.wordpress.com/2012/12/harper-theyre-us.pdf> (Fecha de consulta: 6-02-2019).

${ }^{36}$ Luis Pérez Ochando identifica el ensimismamiento de Barbara con el gótico americano y entiende este como "[...] un tiempo interior, una estancia de silencio en el castillo que Ben se afana en fortificar. La suya es una prisión del alma, un recinto que actúa a la manera de la casa gótica [...]". PÉREZ OCHANDO, Luis, 2013, p. 31. 
recen seguir el mismo patrón de comportamiento. Judy también muere y lo hace cuando decide acompañar a Tom -su pareja- a repostar de combustible la camioneta de Ben e intentar así escapar del lugar todos juntos. Una vez llegan al depósito de gasolina la camioneta se incendia accidentalmente y acaba explotando con ellos todavía en su interior (fig. 2).

El caso de Helen admite ciertos matices, en tanto que es la única de las tres mujeres que muestra un mínimo atisbo de autonomía al enfrentarse verbalmente a su marido en alguna ocasión. Pese a todo, el estrecho vínculo maternal que le une a su hija le obligará a seguir soportando la actitud de su marido hacia ella. ${ }^{37}$ Irónicamente, su hija es la que acaba poniendo fin al matrimonio devorando el cuerpo de su padre y acuchillándola a ella brutalmente hasta la muerte (fig. 3).

Con esta situación se revela que el significado del zombi, como figura metafórica, va a estar definido por su relación con la Familia y la Pareja. El ataque de los muertos vivientes no es más que la proyección física de las tensas relaciones patriarcales hombre/mujer, así como de las relaciones familiares, $^{38}$ la casa el lugar en el que se materializa dicha proyección. De acuerdo con Pinedo, esto se debe a que el terror posmoderno "[...] denaturalizes the repressed by transmuting the 'natural' elements of everyday life into the unnatural form of the monster". ${ }^{39}$ La familia, pese a ser víctima, es también la causa de su propia enfermedad porque, en este contexto, los zombis parecen una consecuencia lógica o una respuesta a las normas patriarcales establecidas. ${ }^{40}$ En definitiva, de forma similar a una enfermedad autoinmune, la familia es la que da origen, simbólicamente, a los zombis.

El único personaje que sobrevive, al menos temporalmente, es Ben. No es algo sorprendente, puesto que, aunque no conocemos nada de su pasado, se trata del único personaje que no mantiene ningún lazo sentimental o familiar. Decimos temporalmente porque el desenlace final será, de facto, fatídico para él. La noche de los muertos vivientes se estrenó en 1968, cuando la indignación y tensión racial estaban en pleno apogeo, por lo que era imposible pasar por alto la idea de que la película era una metáfora de los problemas sociales experimentados por la población afroamericana, sobre todo cuando el único hombre negro es asesinado por la cuadrilla de blancos al final de la película. En este sentido, pese a que Romero y Russo -guionistas del film- han recalcado en multitud de ocasiones que no había ninguna implicación racial en sus mentes cuando eligieron al actor que interpreta a Ben, ${ }^{41}$ no se puede negar que La noche de los muertos vivientes es un reflejo de las revueltas sociales de finales de la década de 1960 y que, por tanto, ambos cineastas no ignoraban del todo lo que estaban haciendo. ${ }^{42}$

En cualquier caso, Romero consigue crear una narrativa que le permite oponerse a la estructura social dominante -la familia, el patriarcado, los roles y estereotipos de género- y gracias a esto sus películas pueden ser abordadas desde una perspectiva más democrática en lo relativo al papel tradicional de la mujer como víctima en el cine de terror. ${ }^{43} 44$ Más democrática porque, aunque todas las mujeres acaban muriendo y su pasividad puede encuadrarse dentro de ese papel que tradicionalmente se les ha asignado dentro del cine de terror, parece que Romero utiliza estos estereotipos para crear un espacio de denuncia que transgrede la narrativa del film y alcanza el plano de la realidad social en el que fue rodada su ópera prima.

Posteriormente, la materialización de este mensaje crítico hacia un modelo social dominado por el patriarcado, articulado gracias a la capacidad metafórica del zombi, se verá reforzado en el remake

\footnotetext{
37 Esta situación es fácil de explicar teniendo en cuenta que después de la Segunda Guerra Mundial, en una etapa de bonanza económica y grandes políticas de apoyo a la familia por parte del gobierno, los estadounidenses abrazaron los ideales de la familia nuclear tradicional, aquella que vivía felizmente en pequeñas casitas de las zonas suburbanas de las grandes ciudades. Un concepto familiar destinado a mantener las distinciones de género como una tarea primordial para ambos progenitores, pero cuyo pilar fundamental era el rol de la mujer como esposa y madre como señala VANDENBERG-DAVES, Jodi, 2014, p. 173. Este mensaje caló hondo en la sociedad norteamericana gracias, sobre todo, al boom cultural de la televisión, desde la que se reforzaron los rígidos roles de género asignados a la Madre y al Padre.

38 WOOD, Robin, 2003, p. 102.

39 PINEDO, Isabel Cristina, 2004, p. 107.

40 SHAVIRO, Steven, 1993, p. 89.

${ }^{41}$ GAGNE, Paul R., 1987, p. 37-38.

${ }^{42}$ GAGNE, Paul R., 1987, p. 38.

43 Para más información relativa al papel tradicional de la mujer como víctima en el cine de terror véase: WILLIAMS, Linda, 1991, p. 2-13; CLOVER, Carol J., 2015; CREED, Barbara, 1986, p. 44-71.

44 PATTERSON, Natasha, 2008, p. 104-105.
} 

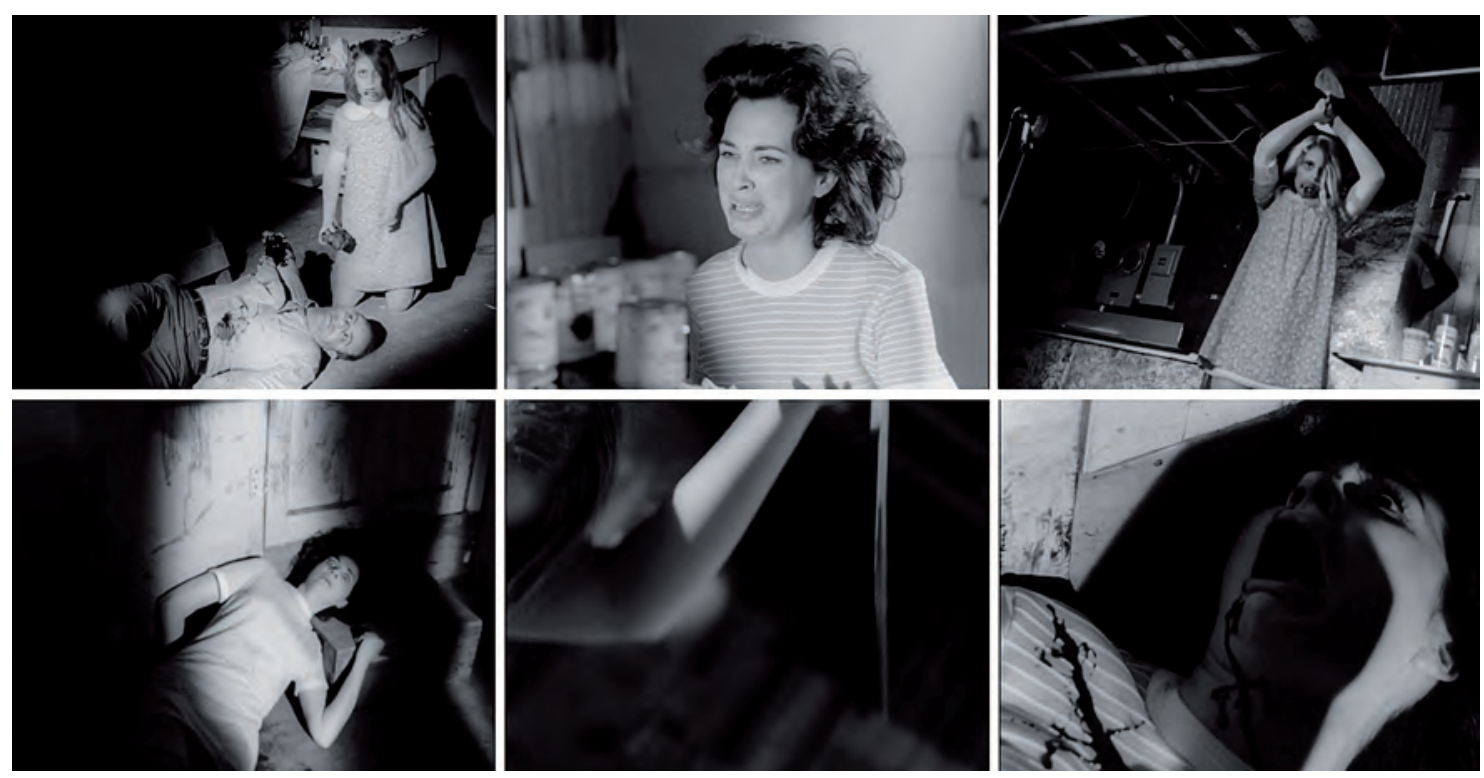

Figura 3. La noche de los muertos vivientes, George A. Romero, 1968.

dirigido en 1990 por Tom Savini. Un remake en el que el propio Romero, encargado del guion, consigue complementar el mensaje de la película original y aportar nuevas ideas en lo relativo a la construcción de los personajes femeninos.

\section{Reviviendo un clásico de la mano de Tom Savini}

El año 1990 trajo consigo una importante noticia para los seguidores más acérrimos del cine zombi de Romero, una de esas noticias que suelen recibirse con cierto escepticismo cuando se tiene en gran estima un film tan emblemático como La noche de los muertos vivientes. Nos referimos, evidentemente, al estreno del remake de la ópera prima de Romero a manos de Tom Savini.

El público reaccionó de formas muy diversas, si bien es cierto que en líneas generales las expectativas no eran para nada halagüeñas. El hecho de que un gran estudio de Hollywood, en este caso Columbia Pictures, se encargara de apoyar la mayor parte de los costes de producción era algo que se observaba con cierto recelo. Lógico, por otra parte, si pensamos que Romero ha sido siempre un director al que le ha gustado gozar de una cierta libertad artística, razón por la que mostraba muchas reticencias a la hora de formar parte de grandes proyectos en Hollywood. Tanto él como Richard P. Rubinstein, cofundador de Laurel Entertainment junto a Romero, "[...] have earned a considerable reputation for refusing to bend to the rules of the Hollywood studio system for financing and distribution, where the money people keep a tight reign on the creative aspects of a film". ${ }^{45}$ No obstante, Romero nunca se ha cerrado a trabajar con grandes estudios que le proporcionaran un mayor presupuesto, tal y como quedó demostrado en Creepshow (George A. Romero, 1982), cuyos derechos de distribución fueron adquiridos por Warner Brothers, o La tierra de los muertos vivientes (Land of the Dead, George A. Romero, 2005), en cuya producción participó Universal Pictures. Romero es bastante taxativo al respecto:

I don't reject the studio system out of hand. I'd like to be able to work with that kind of budget, but I would insist on enough control. It always amazes me why they would hire you at all to take your controls away from you. It doesn't make any sense. I've been in an independent situation all along. ${ }^{46}$

45 GAGNE, Paul R., 1987, p. 59.

46 YAKIR, Dan, 1977, p. 60-65. Citado en WILLIAMS, Tony, 2011, p. 55. 
Así mismo, es habitual pensar el remake como un producto comercial que repite una fórmula que en el pasado tuvo éxito y cuyo objetivo primordial es el de obtener un beneficio económico alto arriesgando poco. ${ }^{47}$ Verevis habla de los remakes como productos "pre-sold", ${ }^{48}$ en tanto que el factor nostálgico hacia la obra original garantiza un colchón mínimo de espectadores que reduce el riesgo a posibles fracasos de recaudación. En este sentido, al menos a priori, este remake no iba a ser una excepción. Romero estuvo de acuerdo en que se hiciera debido a que todas las partes implicadas en la producción de la película original habían sufrido un perjuicio económico enorme como consecuencia de un problema con el copyright, como explica Bishop:

Although the black and white drive-in classic had made millions of dollars following its realease in 1968 , none of the original filmmakers had seen anything like their fair share of the profits. Between questionable distribution practices, bankruptcy filings and the embarrassing fact that the copyright line had accidentally been left off the original print's title [...], Night of the Living Dead was victim of its own success. ${ }^{49}$

Otros autores que se dedican a estudiar el concepto del remake y sus implicaciones, como es el caso de Leonardo Quaresima, consideran que, además de esa postura estrictamente comercial, el remake puede ser concebido como una segunda oportunidad que se le da al texto fílmico:

To give a text a second chance, to allow it to fulfil what it wasn't able to do the first time, does not mean simply giving the characters or the situation a new opportunity. It means providing the text, on the level of its formal structure, its narrative organisation, and its very technological means, a second opportunity. [...] It is a second opportunity offered to the same characters to re-enact a gesture, reconsider a choice, relive an adventure, while retaining the memory of the previous adventure or, better yet, remaining wiser from the previous experience..$^{50}$

Por lo tanto, aunque Romero delega la dirección del remake en su amigo Tom Savini, este aprovecha la oportunidad para reescribir el guion y revisar el film original, dándole esa segunda oportunidad de la que habla Quaresima. Romero revisita su ópera prima, además de por motivos económicos, con la intención de adaptarla al nuevo contexto social e histórico que se vive en 1990, otorgándole una visión más progresista que en la original, " [...] particularly in terms of the feminist issues raised by the first Night's influence on the subsequent development of the genre". ${ }^{51}$

Así, siguiendo la órbita de los movimientos feministas en auge, el cambio principal va afectar al personaje de Barbara, quien abandona el estado catatónico en el que queda sumida en 1968 por una actitud mucho más activa. En la nueva Barbara del remake parecen haber germinado, ahora sí, los ideales de un movimiento feminista que comenzó a florecer a mediados de la década de los sesenta en los Estados Unidos. Resulta difícil entender los cambios que Romero aplica si no tenemos en mente la lucha de las feministas de la Segunda Ola, quienes lucharon por la liberación de la mujer de la opresión cultural, su inclusión en la vida pública y el replanteamiento de los roles de género, sobre todo en lo relativo a la asignación tradicional del rol de esposa y madre simplemente por el hecho de haber nacido mujer. ${ }^{52}$ El fin de la Segunda Guerra Mundial fue, en resumen, una época en la que los roles de género aceptados hasta el momento comenzaron a entrar en conflicto con las ideologías de género progresistas nacidas tras la guerra..$^{53}$ Romero aprovecha el remake para reflejar estos cambios sociales y dar de esta manera una segunda oportunidad a las mujeres de $L a$ noche de los muertos vivientes, consiguiendo así establecer un paralelismo entre el discurso crítico de la película y la realidad social del momento.

En esta nueva versión del clásico de Romero ya no se puede decir que el personaje de Barbara, como indica Gregory A. Waller, "[...] would seem to support certain sexist assumptions about female passivity, irrationality, and emotional vulnerability" ${ }^{54} \mathrm{En}$ cualquier caso, aunque el cambio en el personaje va a ser progresivo conforme haga frente a la violencia patriarcal, ya en la escena del cementerio se nos va a mostrar que nada tiene que ver con su ho-

\footnotetext{
47 VEREVIS, Constantine, 2006, p. 37.

48 VEREVIS, Constantine, 2006, p. 3.

49 BISHOP, Kyle William, 2010, p. 161.

50 QUARESIMA, Leonardo, 2002, p. 80-81.

51 GRANT, Barry Keith (ed.), 2015, p. 230.

52 VANDENBERG-DAVES, Jodi, 2014, p. 224.

53 WEISS, Jessica, 2000, p. 18.

${ }^{54}$ WALLER, Gregory A., 1986, p. 283.
} 

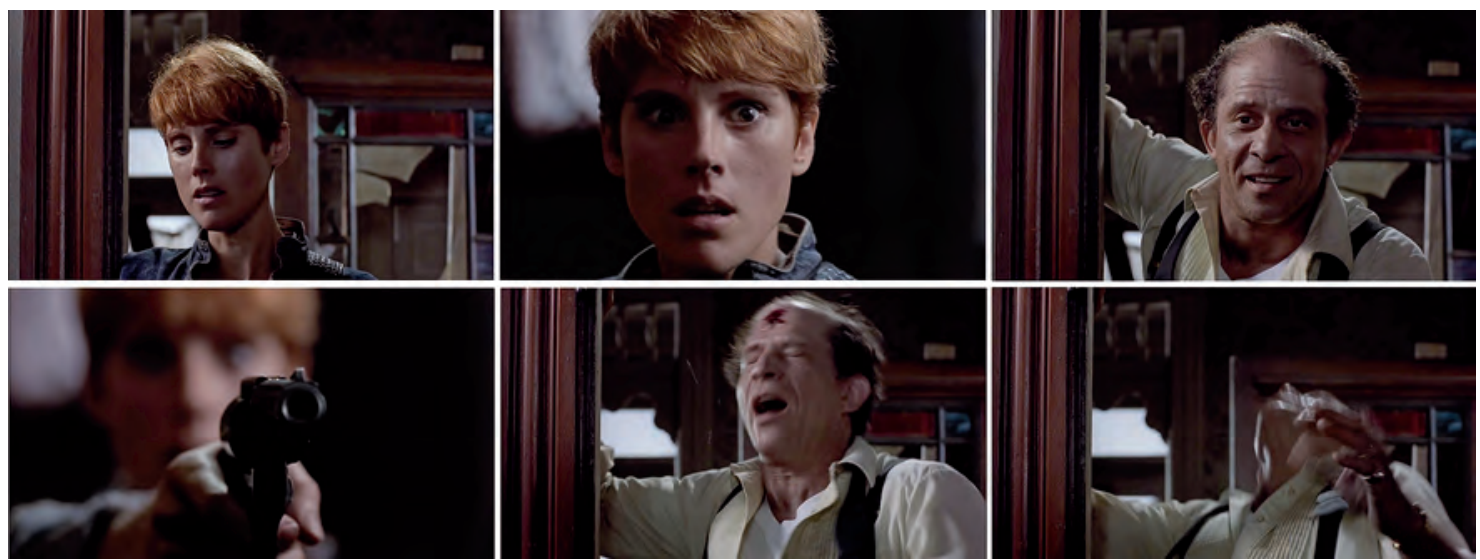

Figura 4. La noche de los muertos vivientes, Tom Savini, 1990.

mónima de 1968. Nos encontramos ante una nueva Barbara que, desde el primer momento y a diferencia de la original, no se limita a huir de aquel zombi que acaba con la vida de su hermano Johnny, sino que se enfrenta a él físicamente.

Aunque no tan notables como los cambios que afectan al personaje de Barbara, las otras mujeres de la casa -Helen y Judy- también reciben cambios significativos que, como señala Harper, se pueden entender como feministas. ${ }^{55}$ Judy y Helen, que en la versión original de 1968 eran fundamentalmente pasivas y se presentaban al espectador realizando tareas asociadas a roles femeninos tradicionales, muestran un mayor grado de autonomía e incluso intervienen en el conflicto masculino tomando la voz cantante. Así, por ejemplo, las discusiones entre Harry y Helen son mucho más intensas, dando a entender sin ambigüedad alguna que existe un abuso físico por parte de su esposo.

Partiendo de esta base, tenemos que tener presente que la premisa del remake es la misma que en la película original, es decir, un grupo de personas se refugian en una casa en la que tendrán que sobrevivir al asedio de los muertos vivientes. Al igual que ocurriera 22 años antes, el conflicto masculino entre Ben y Harry se mantiene e incluso se vuelve más explícito en su lucha por el dominio masculino y el control territorial. Por el contrario, en esta ocasión, todos los personajes acabarán muriendo a excepción de Barbara. Ella sobrevive porque es la única que en todo momento muestra una actitud racional y es capaz de rechazar sin miramientos cualquier lección de comportamiento dada por Harry o Ben. En este sentido, es muy sintomática la frase que le dice a este último cuando le ordena que no pierda los nervios: "Lo que sea que perdí, lo perdí hace mucho tiempo y no perderé nada más. Puedes dejar de hablarme de perder la cabeza cuando dejéis de gritaros el uno al otro como un puñado de niños de tres años".

Sin embargo, su supervivencia conlleva un coste personal debido a que hace uso de una violencia que roza lo irracional. ${ }^{56}$ Irracionalidad que se materializa cuando al regresar a la casa a la mañana siguiente se encuentra con que Harry sigue vivo y lo mata de un disparo en la cabeza (fig. 4). Un acto que, de acuerdo con Grant, se puede interpretar como la respuesta de una mujer al patriarcado ${ }^{57} \mathrm{y}$ como un acto de profesionalismo instintivo ${ }^{58}$ al modo de los personajes masculinos de las películas de

${ }_{55}$ HARPER, Stephen, 2003, p. 8, en línea En: <https://intensitiescultmedia.files.wordpress.com/2012/12/harper-theyre-us.pdf> (Fecha de consulta: 6-02-2019).

56 WILLIAMS, Tony, 2015, p. 245.

57 GRANT, Barry Keith (ed.), 2015, p. 238.

${ }^{58}$ Entendiendo por profesionalismo la existencia de un código moral rígido que determina las acciones de sus personajes. Su integridad moral es prácticamente intachable debido a su compromiso con un sistema de valores que forma parte intrínseca de su identidad, valores inviolables y que se erigen casi como una suerte de estoicismo. 
Howard Hawks; ${ }^{59}$ coincidiendo con Jaime Russell en que la violencia de Barbara se presenta como un acto de represalia más que de venganza personal. Barbara lo ejecuta porque su comportamiento representa todo lo que está mal en el orden patriarcal dominante..$^{60}$

Este profesionalismo del que hablamos se pone de relieve a lo largo del film, manifestando Barbara una determinación que recuerda mucho a aquella que exhiben personajes como el interpretado por John Wayne en Río Bravo (Rio Bravo, Howard Hawks, 1959) o Montgomery Clift en Río Rojo (Red River, Howard Hawks, 1948). ${ }^{61}$ No debe extrañarnos que, siendo Hawks uno de los directores favoritos de Romero y evocado en algunas de sus películas a través de sus personajes ${ }^{62}$-véanse Los caballeros de la moto (Knightriders, George A. Romero, 1981) o El día de los muertos (Day of the Dead, George A. Romero, 1985)-, este recurra a la filosofía del profesionalismo para convertir a Barbara en la heroína que enfrenta el horror de los zombis y la violencia patriarcal. Sea una referencia inconsciente o no, lo que está claro es que el mundo los de muertos vivientes de Romero, como señala Barry Keith Grant, "[...] is a brutally Hawksian one, in which the primary task is survival itself. Being able to survive in this world requires a philosophical detachment and existential determination in order to cope with the zombies physically, psychologically, and spiritually". ${ }^{63}$

En este sentido, Claire Johnston nos dice que en las películas de Howard Hawks "[...] there is only the male and the non-male: in order to be accepted into the male universe, the woman must become a man... [S] he is a traumatic presence which must be negated". ${ }^{64}$ Esta apreciación parece coincidir con las conclusiones a las que Laura Mulvey llega en su estudio sobre la representación de la mujer en el Hollywood clásico, en el que incluye el análisis de algunos films de Hawks: lo masculino equivale a activo y lo femenino a pasivo. ${ }^{65}$ Si aceptáramos ambas premisas como válidas, podría inferirse con relativa facilidad que Barbara es masculinizada desde el momento en el que comienza a exhibir este profesionalismo Hawksiano.

Llegados a este punto la comparación de Barbara con la Final Girl descrita por Carol J. Clover en su análisis sobre las películas del subgénero slasher, el cual alcanza su punto álgido en la década de los ochenta, se hace necesaria e inevitable. La Final Girl, a grandes rasgos, es aquella mujer que sobrevive a la narrativa, bien porque acaba siendo rescatada o porque ella misma consigue acabar con el asesino. Clover la describe como un tanto masculina, un personaje con una mirada activa que en el cine de terror tradicionalmente se reservaba para los personajes masculinos y era castigado con la muerte en el caso de las mujeres. ${ }^{66}$ Por otro lado, si bien describe a la Final Girl como inteligente y capaz de salvarse sin ayuda externa de un hombre, Clover no permite que estas heroínas se definan normativamente como femeninas. ${ }^{67} \mathrm{Su}$ género está "[...] compromised from the outset by her masculine interests, her inevitable sexual reluctance, her apartness from other girls, sometimes her name". ${ }^{68}$ Por lo tanto, aplaudir a la Final Girl como un avance feminista "[...], as some reviews of Aliens have done with Ripley, is, in light of her figurative meaning, a particularly grotesque expression of wishful thinking" ${ }^{69}$

La realidad es que Barbara consigue liberarse de las cadenas del patriarcado, pero asumiendo en el camino algunos de sus preceptos y convirtiéndose, de manera literal, en una mujer masculinizada. Masculinización que no se ve reflejada solamente por la violencia ejercida, sino también por su vestimenta. Pasa de ser una joven recatada (fig. 5) a adoptar un aspecto de pseudo-guerrillera (fig. 6), recordando a personajes tan emblemáticos como el de Sarah Connor en Terminator (The Terminator, James Cameron, 1984) o el de Ellen Ripley en Alien el octavo pasajero (Alien, Ridley Scott, 1979). Un hecho que

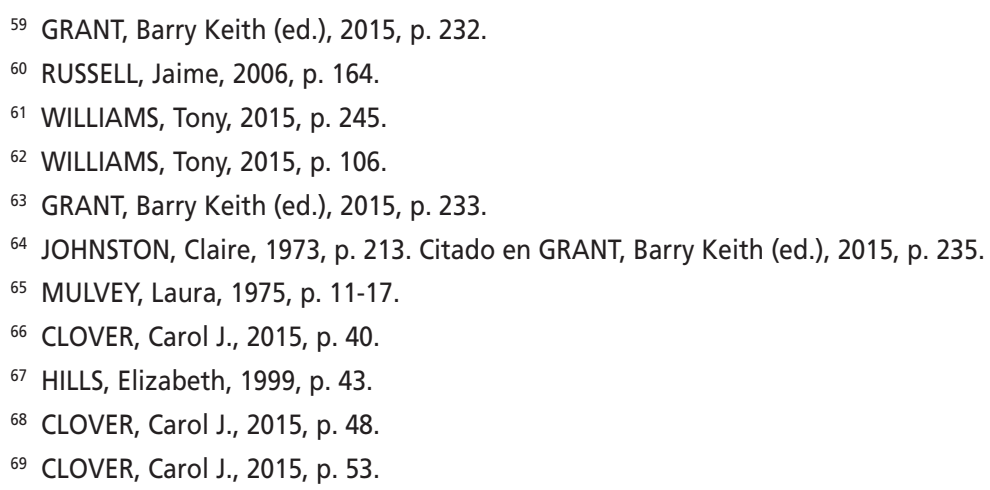




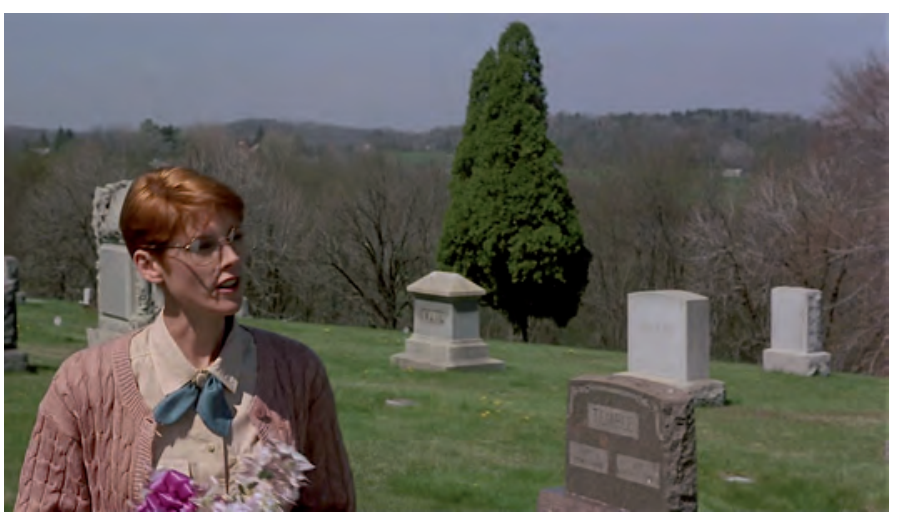

Figura 5. La noche de los muertos vivientes, Tom Savini, 1990.

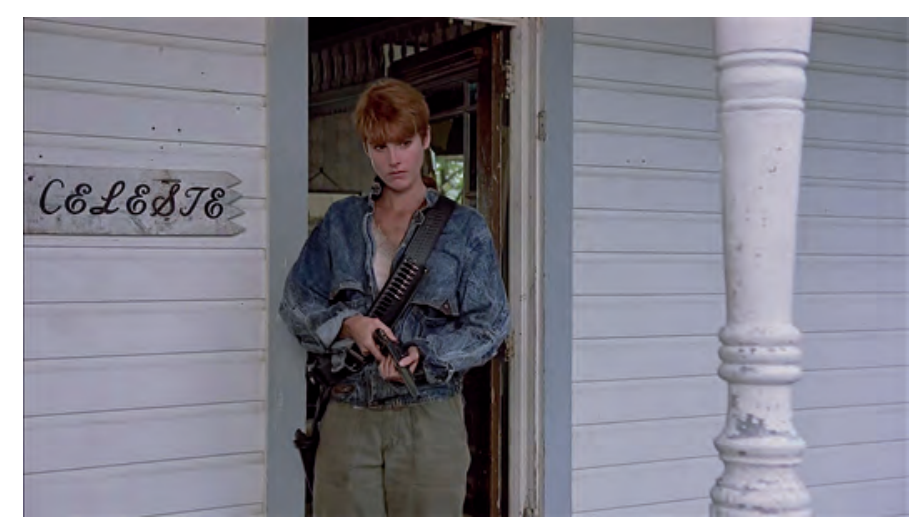

Figura 6. La noche de los muertos vivientes, Tom Savini, 1990.

podría ser negativo en tanto que puede llegar a concebirse como un fetiche o hipersexualización de la mujer, aunque no parece ser este el caso ya que en ningún momento se cosifica su cuerpo ni la vemos desnuda durante el cambio de vestimenta. Esto, lejos de ser una mera interpretación de quien escribe estas líneas, casa con las declaraciones de Romero en una entrevista realizada por Tony WiIliams (2001) para la revista Quarterly Review of Film and Video. Recogemos a continuación un extracto de la misma:

Tony Williams: In your screenplay for Tom Savini's version of Night of the Living Dead (1990) did you mean to suggest that the new version of Barbara is in danger of being contaminated by the male violence she watches at the climax? She also engaged in violence herself during the film.

George Romero: Yes. Well, my idea was that all along she's becoming a guy! She's almost half way there when you first meet her. I was trying a little of that with Sarah in Day [of the Dead]. But Lori Cardille didn't quite get there. We talked about it a couple of times and she tried to do it. But it didn't work. Patty (Tallman) is a stunt woman. That's her trade. ${ }^{70}$

La intención de Romero era convertirla en un hombre y que la violencia masculina le contaminara. De tal forma, la crítica al machismo y al patriarcado parece elaborarse tratando de fortalecer la figura de Barbara como mujer independiente, pero el camino elegido para ello consiste en dotarla de una excesiva masculinidad. Su forma de actuar recuerda en determinados momentos a los modos de comportamiento de la violencia masculina, lo cual la equipara a aquello a lo que hace frente. El problema principal que se deriva de todo esto es que, pese a la importancia que tiene la presencia de personajes femeninos fuertes, una simple inversión de los roles de género refuerza de manera indirecta los resortes del patriarcado.

El orden social colapsa rápidamente debido a la incapacidad de los personajes masculinos de Romero para trabajar juntos, lo que explicaría que Barbara, único personaje capaz de romper con las estructuras de género hegemónicas, sea la única que sobreviva en el remake. Esta afirmación, en cualquier caso, parece tambalearse cuando al final de la película vemos a un centenar de hombres que han conseguido hacerse con el control de la situación y festejan su éxito con un nivel de violencia desmedido hacia los zombis, actuando como un reflejo del conflicto masculino ya vivido en el interior de la casa.

Barbara cierra la película con una frase lapidaria: "We're them and they're us". Esta frase, pronunciada mientras contempla horrorizada la barbarie que llevan a cabo este grupo de hombres, ha generado muchas interpretaciones. Harper entiende que, en un contexto de denuncia del patriarcado y la violencia institucional del hombre, esta se erigiría como un intento por alentar a la audiencia a identificar la opresión de los zombis con la opresión de la mujer. ${ }^{71}$ Por el contrario, Williams considera que esta frase es un tanto ambigua y se puede aplicar tanto a ella como a los hombres que se burlan de los zombis mientras disfrutan de una barbacoa, en tanto que las imágenes finales no

70 WILLIAMS, Tony, 2001, p. 397-411. Citado en WILLIAMS, Tony, 2011, p. 148.

71 HARPER, Stephen, 2003, p. 9, en línea En: <https://intensitiescultmedia.files.wordpress.com/2012/12/harper-theyre-us.pdf> (Fecha de consulta: 6-02-2019). 
solo representan la perspectiva de Barbara sobre un patriarcado repugnante y monstruoso, sino que también cuestionan sus propias motivaciones. ${ }^{72}$

En definitiva, con este nuevo guion Romero profundiza en los problemas de género y crea, especialmente en lo referido al personaje de Barbara, una visión alternativa a la mostrada en 1968. El hecho de que sobreviva en el remake no es algo fortuito, demuestra una empatía de Romero hacia sus personajes femeninos, mientras que a los masculinos continúa escribiéndolos como inadecuados e idiotas. No obstante, Romero señala hábilmente con el dedo, haciendo que nos preguntemos si es este el camino correcto por muy legítima que sea la reivindicación de Barbara.

\section{Conclusiones}

A lo largo de La noche de los muertos vivientes nos encontramos con que los supervivientes del apocalipsis zombi se ven obligados, por lo disruptivo de este acontecimiento, a abandonar los valores que hasta entonces regían su comportamiento, es decir, aquellos impuestos culturalmente por las estructuras de poder previas al colapso social. Partiendo de esta premisa, Romero vincula la supervivencia a la capacidad de abandonar dichos valores, siendo los personajes más propensos a abandonarlos los que tengan más posibilidades de sobrevivir. Así mismo, la capacidad para abandonarlos está determinada por la posición que cada uno de los personajes ocupaba dentro del sistema o estructuras de poder a las que acabamos de referirnos, posición que está estrechamente vinculada a cuestiones que tienen que ver con la clase, la raza y el género. Estos tres factores colocan a las mujeres en una posición marginal respecto de dichas estructuras, por lo que son ellas las que tienen más oportunidades de renunciar a los valores sociales estériles que el sistema capitalista promulga en su propio beneficio. Sin embargo, las raíces del sistema son tan fuertes y profundas en nuestra cultura que, incluso después de ver peligrar su propia existencia, ninguna de ellas será capaz de abandonar los valores que tienen que ver con el patriarcado y los roles de género. Romero utiliza sus muertes como una forma de reprobar el dominio cultural del patriarcado y sus efectos negativos en la mujer.

Es en su guion para el remake de La noche de los muertos vivientes cuando subvierte la pasividad de los personajes femeninos, sobre todo de Barbara, dotándolos de una mayor autonomía y capacidad de decisión propia. En este sentido, podríamos cuestionarnos, como hace Patterson, si el estado catatónico de Barbara en 1968 y su muerte a manos de su hermano Johnny nos dice más acerca de lo nocivo del patriarcado ${ }^{73}$ o si, por el contrario, la actitud heroica de su homónima en 1990 supone una victoria que pone fin a la victimización tradicional de la mujer en el cine de terror tal y como afirma Grant. ${ }^{74}$

La clave de todo este asunto reside en qué aporta Romero al rol de la mujer en el cine de terror masculinizando a Barbara y haciendo que esta se viera contaminada por la violencia masculina de su entorno en un modo similar al de la Final Girl del subgénero slasher. A nivel figurativo esto no aporta nada novedoso, aunque sí lo hace en su relación con la crítica al patriarcado elaborada en ambas películas. Sin esta crítica, una simple inversión de los roles de género podría poner en tela de juicio la naturaleza y efectividad de su liberación y, de hecho, los últimos compases del film así lo hacen notar. En conclusión, aunque en el remake Barbara rompe con el patriarcado y abandona los valores hegemónicos que hasta la irrupción de los zombis condicionaban su forma de actuar, su liberación individual no significa nada mientras que las estructuras de poder imperantes y los valores que estas promulgan sigan sin transformarse.

\section{Bibliografía}

BISHOP, Kyle William. American Zombie Gothic: The Rise and Fall (and Rise) of the Walking Dead in Popular Culture. North Carolina: Mcfarland \& Co Inc, 2010.

BLAKE, Linnie. The Wounds of Nations: Horror Cinema, Historical Trauma and National Identity. Manchester: Manchester University Press, 2008.

BROWNING, John Edgar. "Survival horrors, survival spaces: Tracing the modern zombie (cine)myth". Horror Studies, 2011, vol. 2, no 1, p. 41-59.

CLOVER, Carol J. Men, Women, and Chain Saws: Gender in Modern Horror Film. New Jersey: Princeton University Press, 2015.

COHEN, Jeffrey Jerome. "Monster Culture (Seven Theses)". En: COHEN, Jeffrey Jerome (ed.). Monster Theory: Reading Culture. Minneapolis: University of Minnesota Press, 1996, p. 3-25.

CREED, Barbara. "Horror and the Monstrous-Feminine: An Imaginary Abjection". Screen, 1986, vol. 27, n 1, p. 44-71.

GAGNE, Paul R. The Zombies That Ate Pittsburgh: The Films of George A. Romero. Dodd, Mead \& Company, 1987.

GRANT, Barry Keith. "Taking Back the Night of the Living Dead: George Romero, Feminism, and the Ho-

\footnotetext{
72 WILLIAMS, Tony, 2015, p. 246-247.

73 PATTERSON, Natasha, 2008, p. 110-111.

${ }^{74}$ GRANT, Barry Keith (ed.), 2015, p. 238-239.
} 
rror Film". En: GRANT, Barry Keith (ed.). The Dread of Difference: Gender and the Horror Film. Texas: University of Texas Press, 2015, p. 228-240.

HARPER, Stephen. "They're Us: Representations of Women in George Romero's Living Dead Series". Intensities: the Journal of Cult Media, 2003, en línea. En: $<$ https://intensitiescultmedia.files.wordpress.com/ 2012/12/harper-theyre-us.pdf> (Fecha de consulta: 602-2019).

HERVEY, Ben. Night of the Living Dead. Londres: British Film Institute, 2008.

HILLS, Elizabeth. "From 'figurative males' to action heroines: Further thoughts on active women in the cinema". Screen, 1999, vol. 40, no 1, p. 38-50.

JOHNSTON, Claire. "Women's Cinema as Counter Cinema". En: NICHOLS, Bill (ed.). Movies and Methods. California: University of California Press, 1976, p. 208-217.

KRACAUER, Siegfried. De Caligari a Hitler: una historia psicológica del cine alemán. Barcelona: Ediciones Paidós, 1985

LOWENSTEIN, Adam. Shocking Representation: Historical Trauma, National Cinema, and the Modern Horror Film. New York: Columbia University Press, 2005.

MULVEY, Laura. "Visual Pleasure and Narrative Cinema". Screen, 1975, vol. 16, n 3, p. 6-18.

NAVARRO, Antonio José. El imperio del miedo: El cine de horror norteamericano post 11-S. Madrid: Valdemar, 2016.

NEWITZ, Annalee. Pretend We're Dead: Capitalist Monsters in American Pop Culture. Durham: Duke University Press, 2006.

PATTERSON, Natasha. "Cannibalizing Gender and Genre: A Feminist Re-Vision of George Romero's Zombie Films". En: MCINTOSH, Shawn; LEVERETTE, Marc (eds.). Zombie Culture: Autopsies of the Living Dead. Lanham: Scarecrow Press, 2008, p. 103-118.

PÉREZ OCHANDO, Luis. George A. Romero. Cuando no quede sitio en el infierno. Madrid: Akal, 2013.

PÉREZ OCHANDO, Luis. Noche sobre América: Cine de terror después del 11-S. Valencia: Universitat de València, 2017.

PINEDO, Isabel Cristina. "Postmodern Elements of the Contemporary Horror Film". En: PRINCE, Stephen (ed.). The Horror Film. New Jersey: Rutgers University Press, 2004, p. 85-117.

QUARESIMA, Leonardo. "Loving Texts Two at a Time: The Film Remake". Cinemas: Revue d'Études Cinematogra-phiques, 2002, vol. 12, n³, p. 73-84.
RHODES, Gary D. White Zombie: Anatomy of a Horror Film. North Carolina: McFarland \& Co Inc, 2001.

RUSSELL, Jaime. Book of the Dead: The Complete History of Zombie Cinema. Godalming: FAB Press, 2006.

SÁNCHEZ TRIGOS, Rubén. La orgía de los muertos: Historia del cine de zombis español. Santander: Asociación Shangrila Textos Aparte, 2019.

SEABROOK, William B. La isla mágica: Un viaje al corazón del vudú. Madrid: Valdemar, 2005.

SHAVIRO, Steven. The Cinematic Body (Theory Out Of Bounds). Minnesota: University of Minnesota Press, 1993.

SORLIN, Pierre. Sociología del cine: La apertura para la historia de mañana. México: Fondo de Cultura Económica, 1992.

TUDOR, Andrew. Monsters and Mad Scientists: Cultural History of the Horror Movie. Oxford: Blackwell Publishers, 1989.

VANDENBERG-DAVES, Jodi. Modern Motherhood: An American History. New Jersey: Rutgers University Press, 2014.

VEREVIS, Constantine. Film Remakes. Edimburgo: Edinburgh University Press, 2006.

WALLER, Gregory A. The Living and the Undead: Slaying Vampires, Exterminating Zombies. Chicago: University of Illinois Press, 2010.

WEISS, Jessica. To Have and to Hold: Marriage, the Baby Boom, and Social Change. Chicago: University of Chicago Press, 2000.

WILLIAMS, Linda. "Film Bodies: Gender, Genre, and Excess". Film Quarterly, 1991, vol. 44, n 4, p. 2-13.

WILLIAMS, Tony. Hearths of Darkness: The Family in the American Horror Film. Madison: Fairleigh Dickinson University Press, 1996.

WILLIAMS, Tony. "An Interview with George and Christine Romero". Quarterly Review of Film and Video, 2001, vol. 18, n 4, p. 397-411.

WILLIAMS, Tony. George A. Romero: Interviews. Mississippi: University Press of Mississippi, 2011.

WILLIAMS, Tony. The Cinema of George A. Romero: Knight of the Living Dead. New York: Columbia University Press, 2015.

WOOD, Robin. Hollywood from Vietnam to Reagan and Beyond. New York: Columbia University Press, 2003.

YAKIR, Dan. "Morning Becomes Romero". Film Comment, 1977, vol. 15, n³, p. 60-65. 